\title{
Strain Measurement of Selective Epitaxial Growth (SEG) SiGe Structure by the Nano Beam Diffraction (NBD) Method
}

\author{
$\underline{\text { Sun-Wook Kim}}{ }^{*}$, J. -H. Yoo*, Sang-mo Koo*, and Dae-Hong Ko* \\ * Department of Materials Science \& Engineering, Yonsei University, Seoul 120-749, Korea
}

As conventional methods for scaling down have reached its limit, strain engineering in MOSFETs using embedded $\mathrm{SiGe}, \mathrm{SiC}$ in recessed source/drains has recently been investigated as a potential candidate. For PMOS devices, in which compressive strain induced in channel region improves hole mobility and drive current, SiGe elevated Source / Drain is an efficient way to induce a compressive stress into the $\mathrm{Si}$ channel ${ }^{1,2}$. In this study, the strain distribution in Si channel area and selective epitaxial growth (SEG) SiGe structure was measured by using nano beam diffraction (NBD) method $^{3,4}$.

90nm-thickness $\mathrm{Si}_{1-\mathrm{x}} \mathrm{Ge}_{\mathrm{x}}(\mathrm{x}=0.18,0.3)$ layer was grown on recessed source/drain structure using SEG process by ultra-high vacuum chemical vapor deposition(UHV-CVD) at $550^{\circ} \mathrm{C}, \mathrm{Si}_{2} \mathrm{H}_{6}$ and $\mathrm{GeH}_{4}$ were used as a precursor for Si and Ge, respectively. Micro-structural analysis of SiGe layer and Ge concentration were measured by JEM-2100F field emission electron microscope at $200 \mathrm{kV}$ and EDS analysis. [110] cross-section TEM samples were made using FEI NOVA 600 FIB system for NBD analysis. NBD technique can measure the variation of diffraction spots from the electron diffraction patterns. NBD was done with a $2.5 \mathrm{~nm}$ diameter probe of which size was estimated from the image in a silicon crystal on [110] zone axis (Fig. 1a) and the profile of the probe obtained by Gatan Digital Micrograph software (Fig. 1b). Fig. 1c is the electron diffraction pattern obtained from unstrained $\mathrm{Si}$ area as a reference pattern to calculate the strain of channel region.

Fig. 2 shows TEM cross-section of patterned wafer with selective epitaxial growth $\mathrm{Si}_{1-x} \mathrm{Ge}_{\mathrm{x}}$ on recessed source/drain region with different $\mathrm{GeH}_{4}$ flow rate. No defects were found in case of $20 \mathrm{sccm}$ $\mathrm{GeH}_{4}$ flow rate. Misfit dislocations began to appear at $60 \mathrm{sccm}$. Higher compressive strain in channel region due to larger lattice mismatch resulted in strain relaxation at recessed source/drain.

Fig. 3(a) is a TEM cross-section image of $\mathrm{Si}_{0.7} \mathrm{Ge}_{0.3}$ on recessed source/drain region and corresponding NBD patterns from selected points. And Fig. 3(b) shows the channel strain dependency of intrinsic $\mathrm{Si}_{1-\mathrm{x}} \mathrm{Ge}_{\mathrm{x}}$ on $\mathrm{GeH}_{4}$ flow rate. The profile of $\varepsilon_{\mathrm{xx}}$ along the channel direction shows compressive channel strain near the channel edge is higher than that of the center of channel region. Also, as the Ge concentration increased, there was a distinct increase in compressive strain along the channel direction

In summary, we investigated the strain distribution in $\mathrm{Si}$ channel area and selective epitaxial growth (SEG) SiGe structure by nano beam diffraction (NBD) method. Misfit dislocations were observed in SiGe source/ drain due to strain relaxation at high $\mathrm{GeH}_{4}$ flow rate and higher compressive stress was induced at high Ge content.

\section{References}

[1] K. Ota et al., IEDM Tech. Dig., p27 (2002).

[2] W. Zhang, N.S. Lloyd, K. Osman, J.M. Bonar, J.S. Hamel, and D.M. Bagnall, Microelectron. Eng., 73-74, 514 (2004).

[3] K. Usuda, T. Numata, and S. Takagi, Mat. Sci. Eng. B, 8, 155 (2005).

[4] A. Béché, J. L. Rouvière, L. Clément, and J. M. Hartmann, Appl. Phys. Letts., 95123114 (2009). 

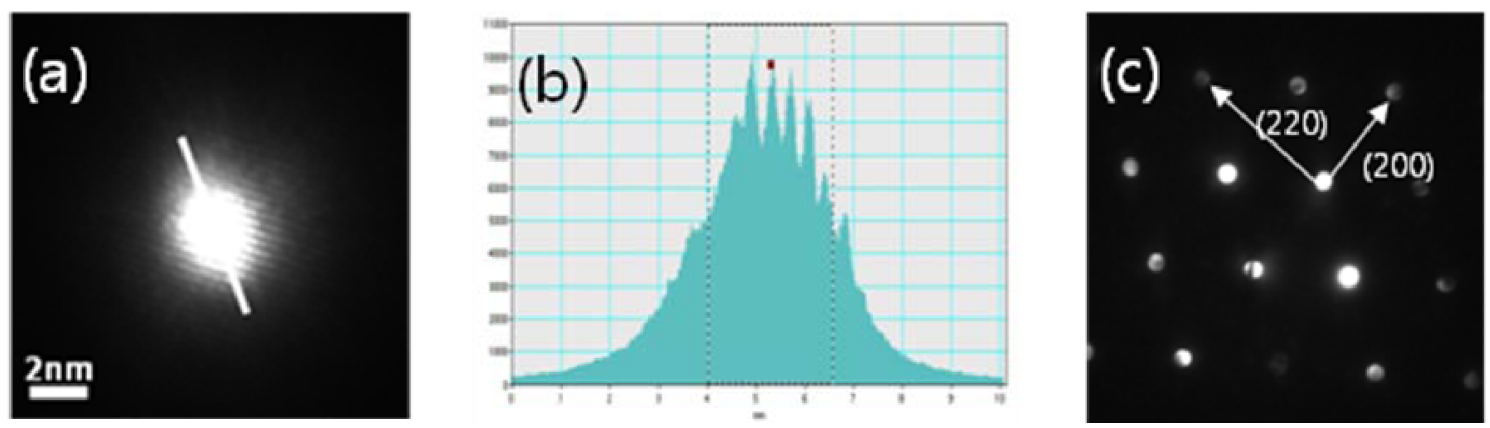

Figure 1. (a) Image of the electron probe in a silicon crystal on [110] zone axis. (b) Profile of the probe along the line in a. (c) Diffraction pattern from unstrained silicon.
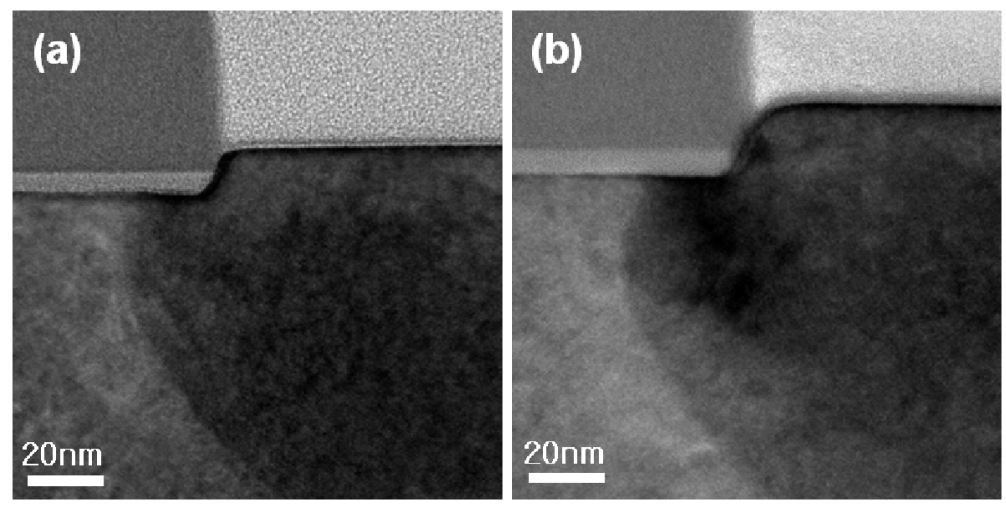

Figure 2. TEM cross-section of selective epitaxial growth SiGe on recessed source/drain region with $\mathrm{GeH}_{4}$ flow rate of (a) $20 \mathrm{sccm}$, (b) $60 \mathrm{scccm}$
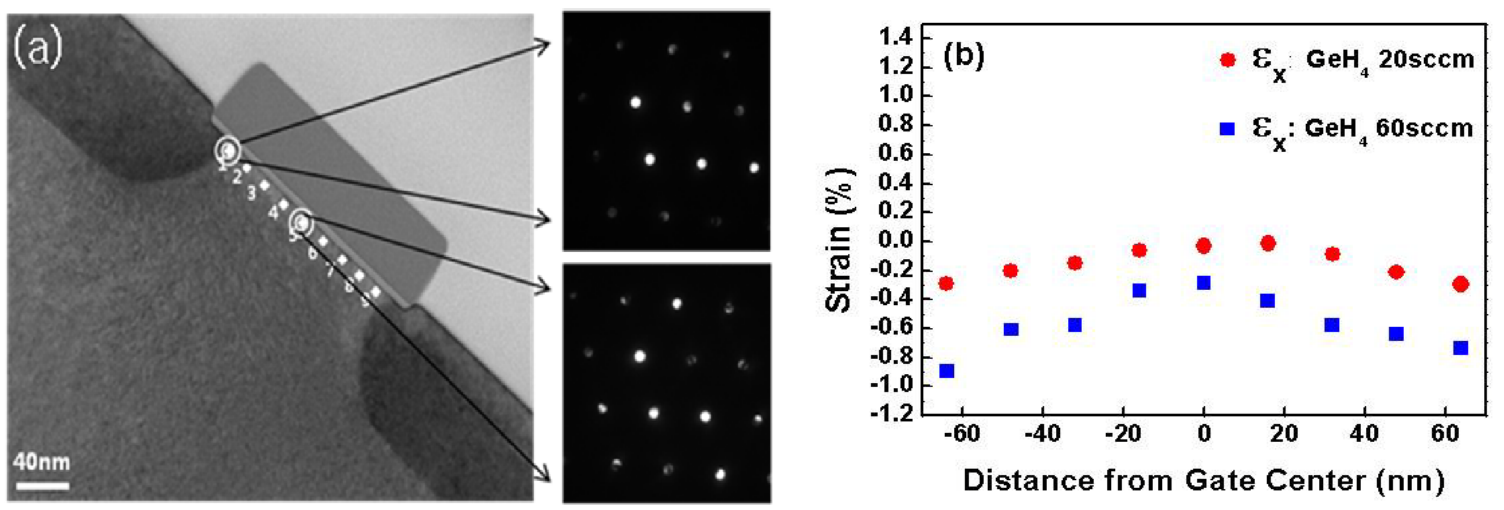

Figure 3 (a) TEM images of $\mathrm{Si}_{0.7} \mathrm{Ge}_{0.3}$ on recessed source/drain region and corresponding NBD patterns along channel direction .(b) Profiles of the channel strain measured by NBD, shows strain dependency of intrinsic $\mathrm{Si}_{1-\mathrm{x}} \mathrm{Ge}_{\mathrm{x}}$ on $\mathrm{GeH}_{4}$ flow rate 